first relates to the location of juvenile and mature wood in the 2 genera and where cuttings are usually taken. Often, Populus cuttings are juvenile because they are taken from stems close to the root crown, not from mature stems in the upper canopy. Therefore, cuttings are unlikely to have preformed floral buds that can be forced in the current year. In contrast, Salix cuttings (particularly those from shrub-form willows) are often taken from mature wood allowing same-year flowering of stock plants. Secondly, the progression from juvenile to mature phase in Salix seedlings can be very rapid ( 2 to 3 y) especially when grown under near optimum conditions; such early maturing species include Salix bebbiana Sarg., S. irrorata Andress., and S. scouleriana Barratt ex. Hook. Conversely, Populus seedlings after more than $5 \mathrm{y}$ of growth in the nursery have yet to become reproductive even after attaining appreciable size.

Some of the willow propagation protocols that follow address using reproductive phase cuttings to produce seed stock plants, and probably would be effective for reproductive phase Populus cuttings; this approach is currently being investigated for Populus fremontii S. Wats. Populus seed production from seed grown stock, however, will likely be a very prolonged endeavor, as with most tree species.

\section{OBTAINING SEEDS}

Two approaches can be used for collecting Salix seeds: 1) collect seeds from wild plants on an annual basis; or 2) bring back either cuttings or seeds to grow plants to establish a seed orchard for future collections.

\section{Annual Collections from Wild Plants}

The identification of female plants before cotton emergence can be determined by examination of the individual flowers or maturing seed capsules on the catkins. The most critical factor in the collection of viable Salix seeds is frequent observation of catkin develop- ment. For this reason, establishment of stock plants in a nursery provides significant advantages over wild-land collections. Catkin harvest is typically planned to coincide with the appearance of cotton emerging from partially opened capsules (Schreiner 1974). I have harvested high percentages of viable seeds if harvest is timed to coincide with this stage of capsule opening. It might be preferable to wait until the capsules are almost fully open, but spring winds can disperse seeds very quickly once capsules reach this stage. Female catkins are placed in paper sacks to capture seeds as the capsules open during drying (Figure 1). In a normal room environment, seeds are released from the catkins in a few days. If the number of catkins collected forms a layer 1 or 2 catkins thick in the sack, the seeds will disperse easily without much oversight. If a thick layer of catkins is placed in the sack, occasional turning and stirring of catkins will be required to facilitate uniform drying and seed release. Avoid plastic bags as they cause moisture buildup and subsequent decomposition.

\section{Using Cuttings or Seeds to Establish Seed Production Areas}

If you desire to establish a seed orchard for specific willow species and seed sources, you can use either cuttings or seeds to start the process. Generally, using cuttings already having reproductive tissues speeds up the process (Figure 2). The development of catkins and flower pollination on recently stuck cuttings can have variable results. With vigorous cuttings of certain species, pollination and seed set can occur soon after sticking, resulting in rapid seed production. However, less vigorous wild-collected cuttings will often result in little if any seed set during the first spring. Insects play a role in pollination of many willows so this fact should be considered if cuttings are flowering in a greenhouse. For Salix cuttings, you must either know the sex of the donor plants having observed catkins the year before, identified the sex by microscopic observation of

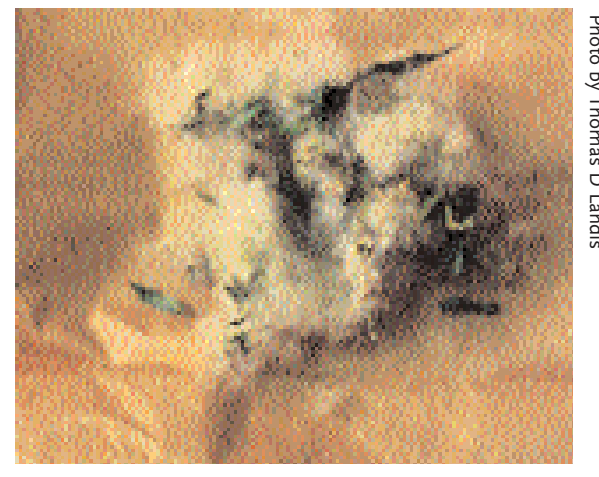

Figure 1. A collection of willow cotton and the paper bag used to transport it back to the nursery.

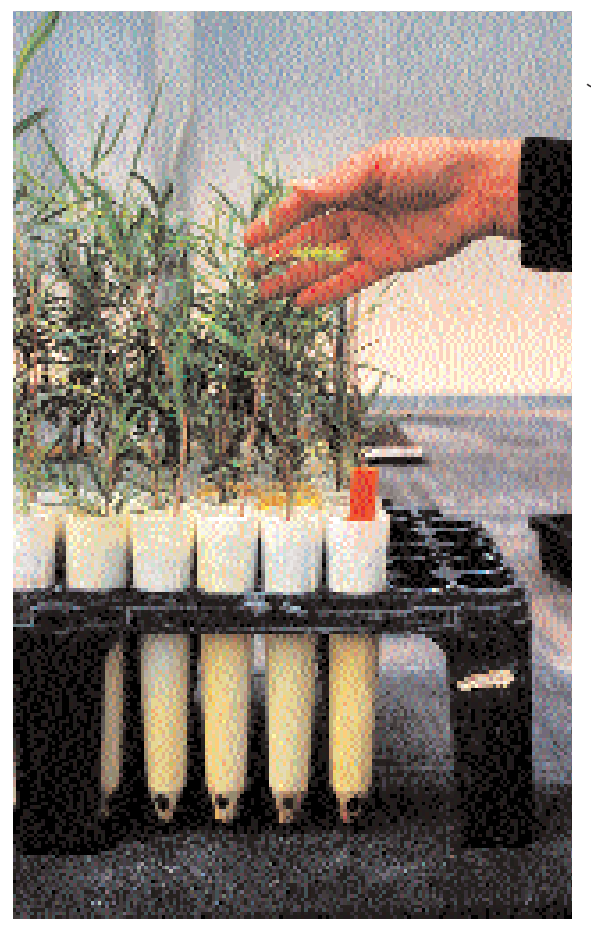

Figure 2. Just a few months after being collected, a female cutting has rooted, flowered, and is dispersing cotton and seeds in the nursery.

reproductive buds (see Landis and others 2003), or collected cuttings from a large number of plants so it is likely that you have collected both sexes. I stick small cuttings into $164 \mathrm{ml}\left(10 \mathrm{in}^{3}\right)$ Ray Leach Super Cells ${ }^{\mathrm{TM}}$ (SC-10) and larger cuttings into 2.81 (1 gal) Treepots $^{\mathrm{TM}}$ (1GTP) (both containers distributed by Stuewe \& Sons Inc, Corvallis, Oregon). I either top-dress 1GTPs with $15 \mathrm{~g}$ of 5 to 6 mo controlled release fertilizer (CRF) Osmocote Plus $15 \mathrm{~N}: 9 \mathrm{P}_{2} \mathrm{O}_{5}: 11 \mathrm{~K}_{2} \mathrm{O}$ (Scott's Company, Marysville, Ohio) or

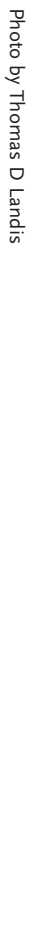

.

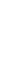


incorporate $3.5 \mathrm{~kg} / \mathrm{m}^{3}\left(6 \mathrm{lb} / \mathrm{yd}^{3}\right)$ for SC10. I tag plants for gender, harvest and clean seeds, and sow seeds to produce initial containerized seedlings. By summer, small stock plants from cuttings can be transplanted into 1GTPs ( $15 \mathrm{~g} 3$ to 4 month CRF) and the larger stock plants can be planted into seed orchards. During the second growing season, expect abundant catkin production and enough seeds for large-scale seedling production. By fall, all remaining stock plants are transplanted to the seed orchardmales and females can be mixed to enhance pollination.

The process is similar if seeds are collected. Frequent field observations of willow stands of known species will allow seed collection if female plants are present and are flowering or dispersing seeds. If collection sites are remote, it may be possible to identify and tag female plants a year in advance and estimate seed maturation date by observing catkin development so that a well-timed collection trip will yield ripe catkins the following year. Seeds can be cleaned and seedlings grown as described below. Seedlings generally grow the first year in SC-10s and are transplanted into
1GTPs during winter or spring. The plants can be tagged for gender after catkins appear which can be as early as the second year for early maturing species (for example, S. bebbiana, S. irrorata, S. scouleriana). Once the sex is know, plants can be moved to the seed orchard as described above.

\section{OTHER CONSIDERATIONS THAT MAY AFFECT RIPARIAN PLANTING STOCK PRODUCTION}

The difficulties encountered in getting an accurate species identification for Salix species may complicate restoration activities; however, the lack of positive identification should not necessarily stop propagation endeavors. In addition, the stock size for outplanting will greatly influence the lead time needed to produce plant materials for a riparian restoration project.

Positive species identification is obviously preferred for any propagation activity. A case can be made, however, that because of the difficulty in willow species identification an alternative approach may be acceptable if: 1) the willows are determined to be native or any exotic willows can be readily identified and disregarded; 2) the willows are collected from the watershed to be restored; 3 ) the growth characteristics of the willow species present in the watershed are appropriate for the restoration purpose and are consistent with the vast majority of the future planting sites; and 4) if necessary, propagules can be collected and kept separate for each individual wild stock plant throughout the propagation process. This final recommendation will allow the seedlings of an individual species to be differentiated at outplanting in case more than 1 species has been harvested during propagule collection. Otherwise, vegetative characteristics may be the only key to separating species until catkins develop.

\section{STANDARD CONTAINER SEEDLING PRODUCTION PROTOCOL}

The most common container stock type we use for montane riparian restoration is 1GTP containers. This container size is generally adequate for acceptable rates of
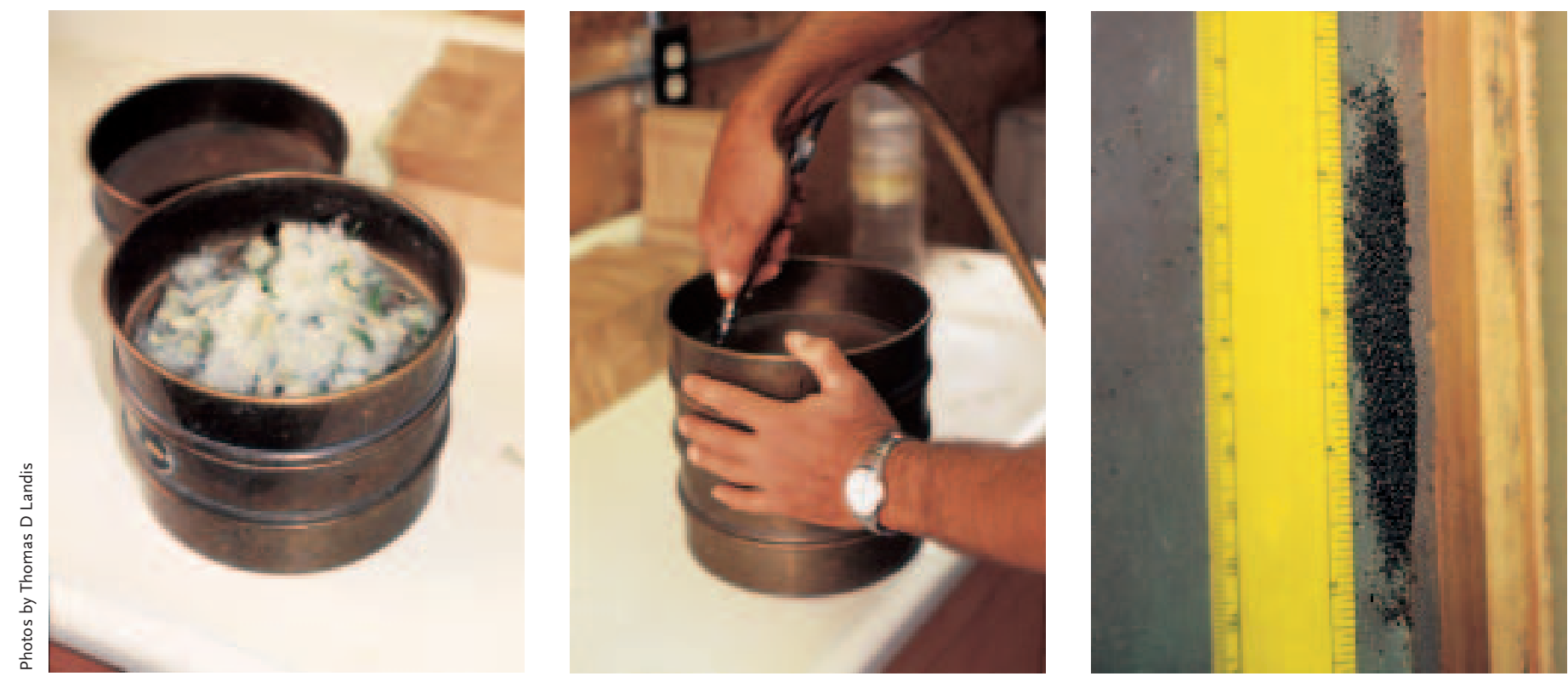

Figure 3. Three soil sieves are needed to clean seeds. The bottom sieve is where the seeds collect.

Cotton and seeds are placed in the middle sieve. The top sieve holds the cotton from blowing out when a stream of compressed air is blown across it. The cotton remains in the middle sieve and clean seeds are deposited in the bottom. 


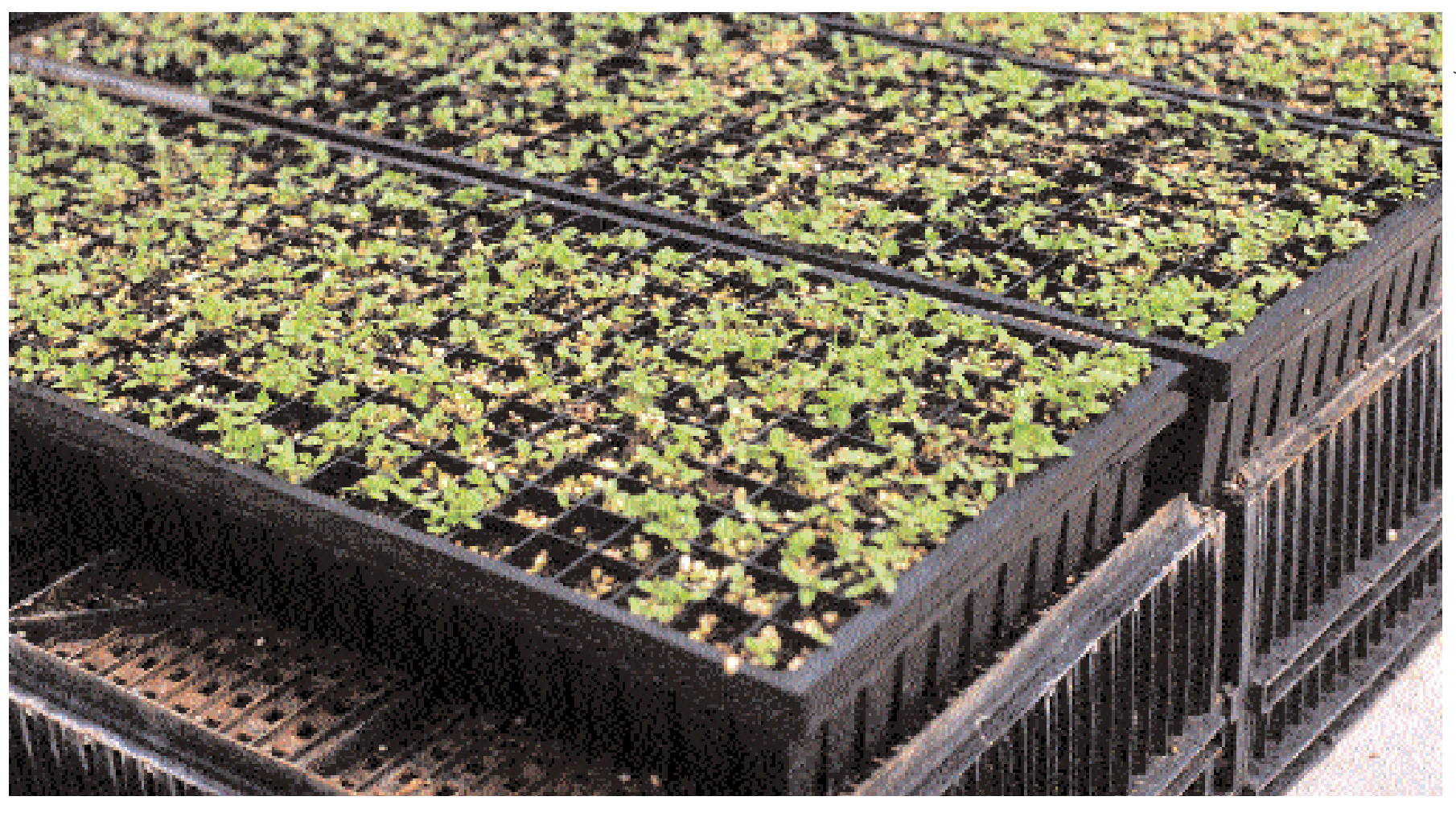

Figure 4. Willow seedlings growing in mini-plugs prior to being transplanted into SC-10 containers.

survival with little aftercare, except protection from cattle and elk. In lower elevation cottonwood forests, 1GTP stock can be used but typically requires supplemental watering for several years to become established. We use small volume "mini-plugs" to maximize greenhouse space for starting the crop, transplant up to SC-10 containers, and finish the crop cycle in 1GTP containers.

\section{Seed Cleaning}

Once seeds are harvested from wild stands or on-site seed orchards, they can be cleaned using an air stream and soil screens similar to that described for Populus by Schreiner (1974). A compressed air source and a set of 3 soil screens in a series from top to bottom of $250 \mu \mathrm{m}$ (\# 60), 500 $\mu \mathrm{m}$ (\# 35), $125 \mu \mathrm{m}$ (\# 120) are employed; the dry catkins containing open capsules are placed between the $250 \mu \mathrm{m}$ and 500 $\mu \mathrm{m}$ screens (Figure 3). A jet of compressed air is blown through the top screen in a swirling fashion; the seed is dislodged and sifts through to the $125 \mu \mathrm{m}$ screen. The cotton and empty catkins re- main on the $500 \mu \mathrm{m}$ screen. Seeds can also be cleaned with vacuum systems (see Dawes 2003; Day and others 2003).

\section{Seed Germination}

At the Los Lunas Plant Materials Center in New Mexico, we germinate willow seeds within a few days of cleaning in "mini-plug" containers having 512 cavities each $14 \times 14 \times 29 \mathrm{~mm}(0.5 \times$ $0.5 \times 1.1$ in [for short term growth -2 to $3 \mathrm{wk}$ ]) or 341 cavities each $19 \times 19 \times 63$ $\mathrm{mm}(0.75 \times 0.75 \times 2.5$ in [for longer term growth -4 to $6 \mathrm{wk}]$ ). We rely on miniplugs because of space restrictions on our automated watering bench that precludes large-scale germination in larger containers. The germination medium is a standard sphagnum peat moss and perlite mix of fairly coarse texture. The coarse texture allows the small Salix seeds to infiltrate between the particles of peat moss, allowing optimum aeration, moisture, and light.

One difficult task is hand seeding. Precision is very difficult because willow seeds are very small (the largest being about $1 \mathrm{~mm}$ in length and 0.3 to $0.5 \mathrm{~mm}$ in width). Adding a diluent of similar size might be of some benefit in achieving more precise sowing by hand. The seeds are usually sufficiently clean that an automated seeder typically used for bedding plant seeds of similar shape and size would probably be effective if very large-scale seeding was envisioned.

\section{Mini-plug Irrigation}

The plug medium surface must be kept continuously moist; germination of willow seeds is often apparent after $1 \mathrm{~d}$ as noted by the swelling and separation of the cotyledons. Our greenhouse watering bench has mini-sprinklers and automatically waters plug trays once a day (Figure 4). The bench is covered with a coppercoated fabric (Texel Tex- $\mathrm{R}{ }^{\circledR}$ Forestry Fabric, Texel Inc, Quebec, Canada) to reduce root egress from the plug cells; this fabric covers a filter fabric (Dewitt soil separator fabric) which acts to pull excess water out of plug cells via capillary water movement. Soluble fertilizer is applied once or twice a week at a rate of $200 \mathrm{mg} / \mathrm{l}(\mathrm{ppm})$ 


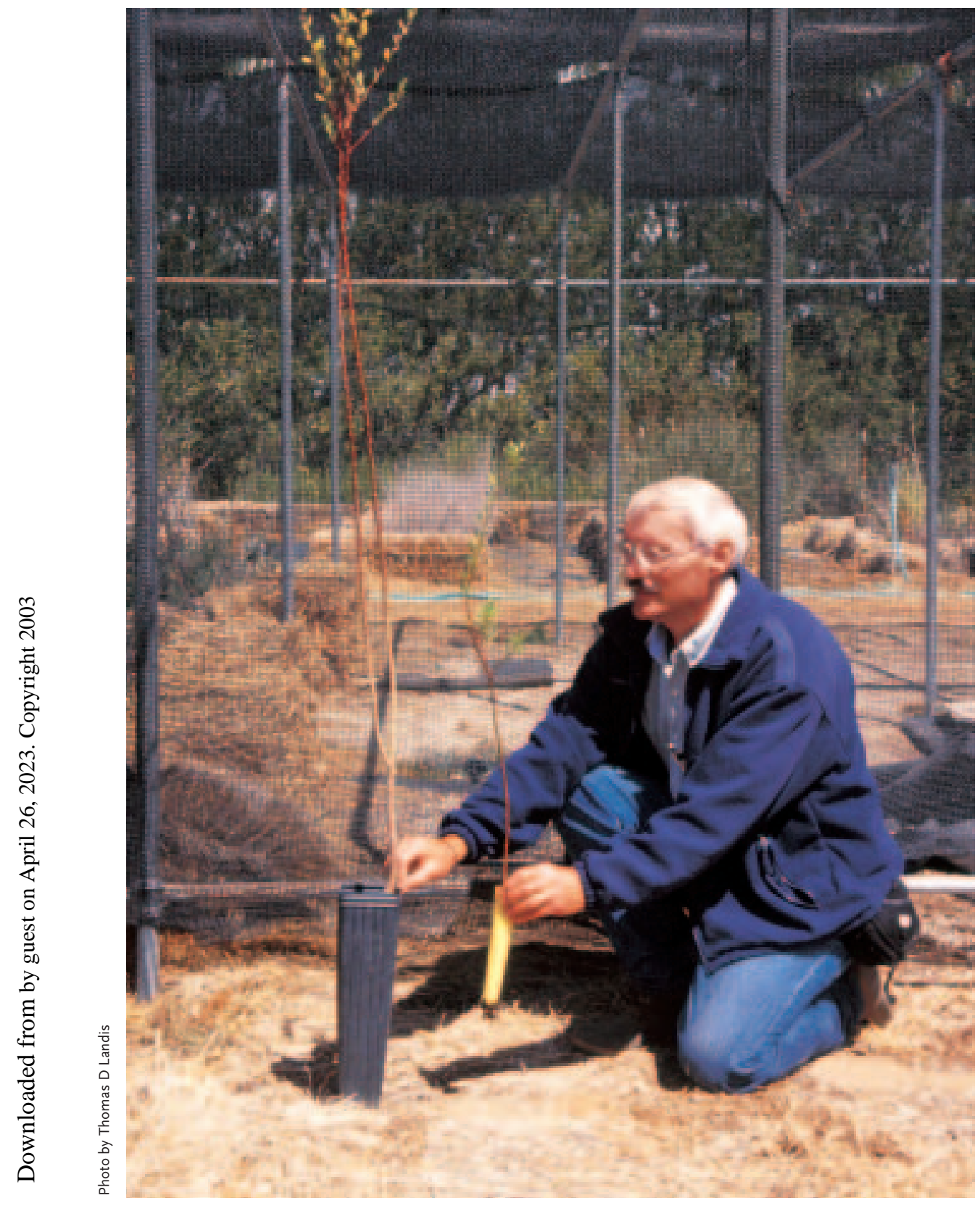

Figure 5. A typical seedling of S. irrorata growing in a 1GTP (left) and SC-10 (right) after 2 and 1 growing seasons, respectively.

nitrogen $\left(20 \mathrm{~N}: 10 \mathrm{P}_{2} \mathrm{O}_{5}: 20 \mathrm{~K}_{2} \mathrm{O}\right.$ Peat Lite Special; Peters Professional, Scott's Company, Marysville, Ohio). Ideally, the plugs are transplanted as soon as the root system is sufficient to keep the soil plug intact ( 3 to $6 \mathrm{wk}$ depending on species and plug size).

\section{Transplanting into SC-10 Containers}

Our medium is a mix of 2 parts Sun-
Bellevue, Washington) with 1 part perlite (v:v) that has $2.7 \mathrm{~kg}(6 \mathrm{lb})$ of CRF incorporated per $0.765 \mathrm{~m}^{3}\left(1 \mathrm{yd}^{3}\right)$ of medium. For plants started in the greenhouse during spring, 5- to 6-month release CRF is used, but for summer grown material 3- to 4month release CRF is incorporated.

Filled SC-10 containers are dibbled to provide a hole for the mini-plug seedling. Thinning seedlings is often required and can be completed as the mini-plugs are transplanted into the SC-10 containers if seedlings are large enough to make clipping feasible. Otherwise, thinning is accomplished after some growth has occurred in the SC-10 containers. The mini-plug seedling root ball is removed using a flat powder spatula having a blade about $6 \mathrm{~mm}(0.25 \mathrm{in})$ wide and $30 \mathrm{~mm}(1.2$ in) long attached to a handle. The blade is plunged along the side of root ball and the seedling plug is levered out of the cell. The plug is dropped into the dibbled hole and the medium is pressed around the root ball with fingers. Top watering firms and fills any voids around the plug.

\section{Transplanting into Treepots ${ }^{\mathrm{TM}}$}

Transplanting into 1GTPs usually occurs in the late summer of the first year or spring of the second year. The containers are filled with an aged bark:pumice:peat medium (55:35:10; v:v:v) and dibbled with a SC-10-size planting dibble. CRF is top-dressed at planting or soon thereafter. For pots transplanted in late spring, a 5- to 6month release CRF is used at a rate of $15 \mathrm{~g}$ $(0.5 \mathrm{oz})$ per pot. Seedlings transplanted later in the summer receive a similar rate of 3- to 4-month release CRF. While the plants are establishing themselves in the larger container, irrigation is usually applied 3 times per week. Plants are typically grown without shade. Watering frequency during the rapid growth phase is every day for large riparian plants with substantial leaf areas.

\section{SEEDLING GROWTH RATES FOR SEVERAL WILLOW SPECIES}

Examples of height and root collar diameter (caliper) growth for several willow species grown in SC-10s with moderate CRF rates are described below as well as for Salix exigua (Nutt.) in larger intermediate containers with high CRF rates. The growth enhancement provided by larger containers with high nutrient levels has been confirmed during the 2003 production season for other species including $S$. ir- 
rorata and S. bebbiana. One aspect of this willow seedling growth data requires explanation-for some species, seeds from stock plants of montane species grown in the desert environment of the Los Lunas Plant Materials Center (elevation $1463 \mathrm{~m}$ [4800 ft]) have been used. It appears, based on the range of willow seed dispersal dates presented by Zasada and others (2000), that seeds are generally produced in our seed orchard at least 1 mo earlier than would be expected from wild collections of montane willows. An example of a typical SC-10 and 1GTP are provided in Figure 5.

\section{Salix irrorata}

Male and female cuttings of S. irrorata were collected from the Wilderness District of the Gila National Forest in southwestern New Mexico and rooted at the Los Lunas Plant Materials Center nursery. After $1 \mathrm{y}$, stock plants growing in 1GTP containers were tagged by sex and then transplanted into a seed orchard established in organic rich nursery beds. After $4 \mathrm{y}$, stock plants were $7 \mathrm{~m}$ tall. Seedlings (sown in late April - early May) growing in SC-10 containers for 1 growing season averaged $62 \mathrm{~cm}$ (24 in) in height and $5 \mathrm{~mm}$ (0.2 in) in caliper measured at the top of the container. After transplanting and growing in 1GTPs for another year, plants averaged $2.6 \mathrm{~m}$ $(8.5 \mathrm{ft})$ in height and $14 \mathrm{~mm}(0.55 \mathrm{in})$ of caliper.

\section{Salix bebbiana}

In March 2001, USDA Forest Service personnel collected $S$. bebbiana cuttings from 2 stands at approximately $2400 \mathrm{~m}$ $(7875 \mathrm{ft})$ elevation, and in June they collected seeds from a wild stand $(2700 \mathrm{~m}$ [8860 ft]) on the Apache-Sitgreaves National Forest in east central Arizona. The cuttings were stuck into 1GTP and the following year (2002) they produced seeds. Seedlings were grown $1 \mathrm{y}$ in SC-10s and transplanted the following year into 1GTPs. Mean heights of 0.5 and $1.6 \mathrm{~m}$ (20 in and $5.2 \mathrm{ft}$ ) and mean calipers of 4.4 and $13 \mathrm{~mm}$ (0.17 and $0.51 \mathrm{in})$ were achieved after 1 and 2 growing seasons for the 2001(sown mid June) and 2002 (sown early May) seedling sources, respectively.

\section{Salix scouleriana}

Cuttings for $S$. scouleriana stock plants were collected from 1 male and 1 female plant at an elevation of $2900 \mathrm{~m}(9570 \mathrm{ft})$ within the Carson National Forest in north-central New Mexico. These cuttings produced seeds, and the resulting full sib seedlings are maintained in large pots as seed sources. These 2-y-old seedling stock plants yielded seeds in early May and the resulting seedlings, grown in SC-10s, had a mean height and caliper of $28 \mathrm{~cm}$ (11 in) and $3.5 \mathrm{~mm}$ (0.14 in), respectively, after 1 growing season.

\section{Salix exigua}

Seeds of coyote willow (Salix exigua Nutt.) were collected in early June from an individual female thicket in the Middle Rio Grande Valley. The mini-plug seedlings were transplanted into SC-10 containers with either a moderate (3.5 $\left.\mathrm{kg} / \mathrm{m}^{3}\left[6 \mathrm{lb} / \mathrm{yd}^{3}\right]\right)$ or high $\left(7.1 \mathrm{~kg} / \mathrm{m}^{3}[12\right.$ $\left.\mathrm{lb} / \mathrm{yd}^{3}\right]$ ) dose of incorporated CRF (3- to 4-mo release). Additional seedlings were transplanted at the same time into D16 (262 $\left.\mathrm{ml}\left[16 \mathrm{in}^{3}\right]\right)$ and D40 (656 $\mathrm{ml}$ [40 $\mathrm{in}^{3}$ ]) Deepot ${ }^{\mathrm{TM}}$ (Stuewe and Sons Inc) containers containing the same soil-less mix with the high dose of CRF.

Relative to seedlings grown in SC-10 containers with moderate nutrient levels, mean height growth was increased $29 \%, 46 \%$, and $93 \%$ for the SC-10, D16, and D40 seedlings with high nutrient levels. Similarly, increases in mean caliper of $15 \%, 51 \%$, and $78 \%$ were noted for the SC-10, D16, and D40 seedlings with high nutrient levels.

\section{Salix arizonica Dorn}

Arizona willow is classified as a sensitive species by the USDA Forest Service, as a highly safeguarded species by the Arizona Native Plant Law, and has a global rank of rather rare (G3) and state rank of rare (ARPC, undated). USDA Forest Service personnel collected seeds of S. ari- zonica in early July 2002 from 2 previously identified female plants on the Apache-Sitgreaves National Forest. After 8 wk growth in SC-10s, the mean heights and calipers were 11 to $15 \mathrm{~cm}$ (4 to 6 in) and 2.2 to $2.3 \mathrm{~mm}$ (0.1 in), respectively.

\section{MORE INFORMATION}

A more detailed description of techniques we use for riparian restoration, including nursery production of other containerized species, field production of pole cuttings, and descriptions of planting projects in the southwestern US can be found in Dreesen and others (2002) available on-line at URL: http://www.rngr.net/Nurseries/ Publications/Proceedings/2001/ dreesen.pdf.

\section{SUMMARY}

The rapid growth rate of Salix seedlings and their almost immediate germination are appreciable advantages for seed propagation. The small seed size and the potential difficulties in collecting seeds from wild stands are among the problems that should be considered before initiating Salix seedling propagation. The rapid transition from juvenile to reproductive phase for some willow species offers benefits in establishing seed stock plants with considerable genetic diversity. Large planting stock with enhanced probability of establishment in disturbed riparian areas can be produced in 2 growing seasons.

\section{REFERENCES}

[ARPC] Arizona Rare Plant Committee, Falk M, coordinator. Undated. Arizona rare plant field guide.

Dawes D. 2003. Using a shop vacuum to clean Salicaceae seeds. Native Plants Journal 4:140. 


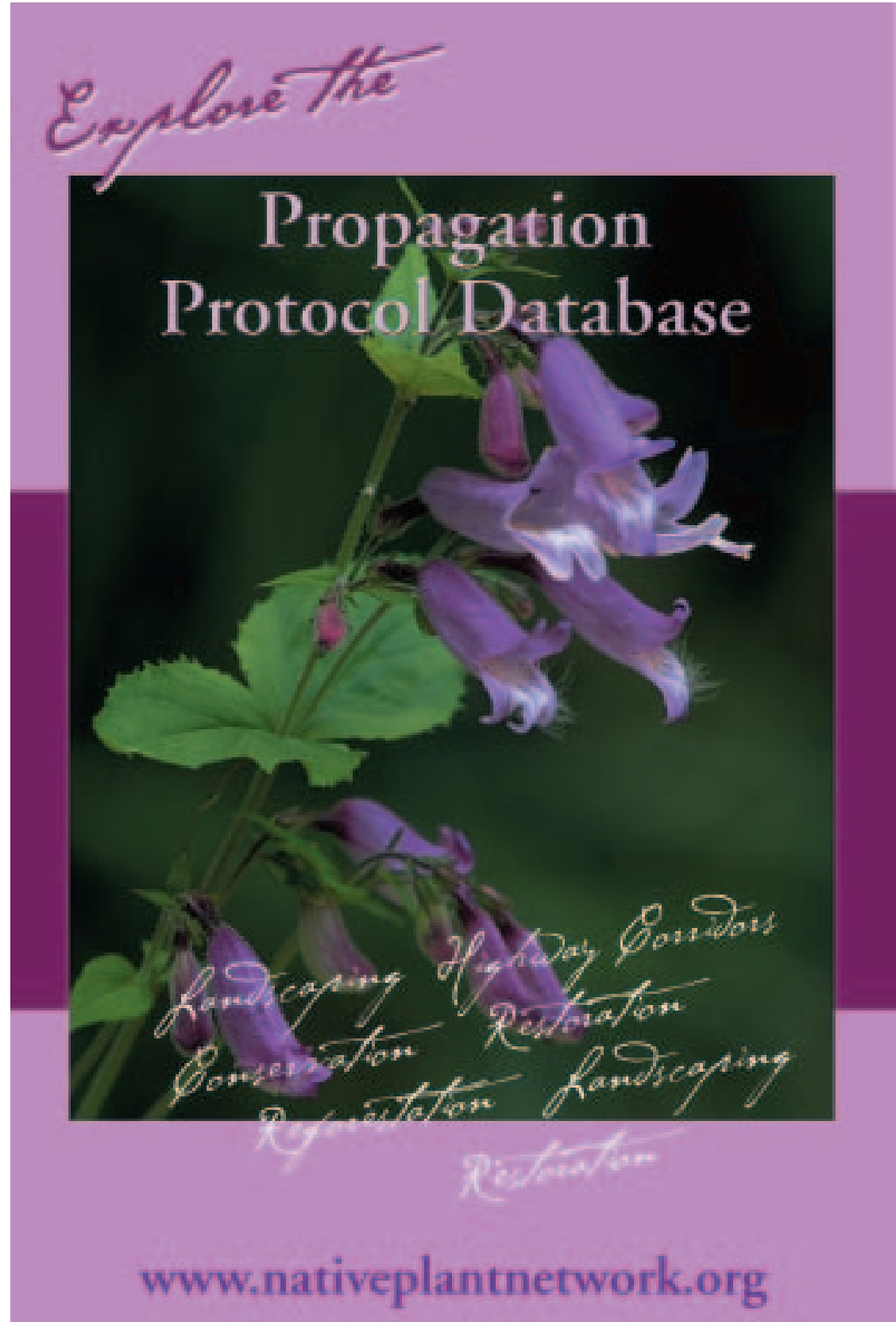

\section{Your free, searchable dacabase of native plant production methods and information center.}

\section{A service of Native Plants Journal. Contact us to exchange your research or subscribe to Native Plants Journal.}

Day RA, Walter RP, Kozar JJ, Bricker SJ, Bowers JG. 2003. Propagation protocol for bareroot bigtooth and quaking aspen using seeds. $\mathrm{Na}$ tive Plants Journal 4:125-128.

Dreesen D, Harrington J, Subirge T, Stewart P, Fenchel G. 2002. Riparian restoration in the Southwest: species selection, propagation, planting methods, and case studies. In: Dumroese RK, Riley LE, Landis TD, technical coordinators. National proceedings: forest and conservation nursery associations1999, 2000, and 2001. Ogden (UT): USDA Forest Service, Rocky Mountain Research Station. Proceedings RMRS-P-24. p 253-272.

[ITIS] Integrated Taxonomic Information System. 2002. URL:http://www.itis.usda.gov (accessed 5 Jul 2003).

Landis TD, Dreesen DR, Dumroese RK. 2003. Sex and the single Salix: considerations for riparian restoration. Native Plants Journal 4:110-117.

Schreiner EJ. 1974. Populus L. Poplar. In: Schopmeyer CS, technical coordinator. Seeds of woody plants in the United States. Washington (DC): USDA Forest Service. Agriculture Handbook No. 450

Zasada JC, Douglas DA, Buechler W. 2000. Salix L. Willow. In: Bonner FT, technical coordinator. Woody plant seed manual interim website. URL: http://www.wpsm.net/Salix.pdf (accessed 5 Jul 2003).

\section{AUTHOR INFORMATION}

\section{David R Dreesen}

Horticulturist

USDA Natural Resources

Conservation Service

Los Lunas Plant Materials Center 1036 Miller Street, SW

Los Lunas, NM 87031

David.Dreesen@nm.usda.gov www.nativeplantnetwork.org

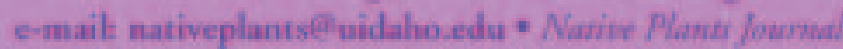
Universiny of Idahe Pross, PO Box 444416, Moscuns ID $83844+4416$ 